Chapter 4

\title{
Plasma Electrolytic Oxidation of Valve Metals
}

\author{
Alex Lugovskoy and Michael Zinigrad \\ Additional information is available at the end of the chapter \\ http://dx.doi.org/10.5772/54827
}

\section{Introduction}

Plasma electrolytic oxidation (PEO) is also known as micro-arc oxidation and spark anodizing is often regarded as a version of anodizing of valve metals $(\mathrm{Mg}, \mathrm{Al}, \mathrm{Ti}$, and several others) and their alloys. Indeed, the essence of both anodizing and PEO is the production of oxide layers on a metal surface by the action of electricity in a convenient electrolyte. An oxide layer has a complex composition and includes various oxides of a base metal, alloy additives and species coming from the electrolyte. For both anodizing and PEO, an oxide layer forms due to electrochemical oxidation of the metal constituents and inclusion of some components of the electrolyte with possible further interactions in the vicinity of the electrode.

However, some features of PEO are clearly different than those of the anodizing. Normally, low-voltage direct currents are used for anodizing and the formation of the oxide layer occurs under a quiescent regime. The produced layer has relatively homogeneous structure with more or less evenly distributed blind pores. The thickness of an oxide layer is limited by 20-50 $\mu \mathrm{m}$ for most cases, because the electrical conductivity of the oxide layer is low and the formation of the layer effectively breaks the electric circuit in the cell. It can be said that the formed layer "passivates" the metal surface in the course of anodizing and thus prevents its own further growth (Fig. 1, stages I - II). It deserves to be notes that sparking is considered undesirable for anodizing, because it is an indication of cracks and inhomogeneities in the formed layer.

For PEO, significantly higher voltages and (normally) alternating currents cause intense sparking due to micro-arc discharges that break down the oxide layer (Fig.1, stages I - III). Extreme temperatures and pressures [1] develop in the discharge channels and cause complex phase-transformation processes that result in the production of a compact, thick hard layer, which often has attractive abrasion and corrosion resistances. Although PEO layers have a relatively high porosity [2], they can effectively protect the base metal against corrosion because the pores formed by a discharge can subsequently "heal" by molten oxides due to 
high local temperatures in the vicinity of plasma discharge channels [3] and are therefore impermeable to corrosion media. The improved corrosion stability of PEO-treated metals as compared to bare metals has been reported for aluminum [4-8] and magnesium alloys (see, for instance, $[9,10])$.

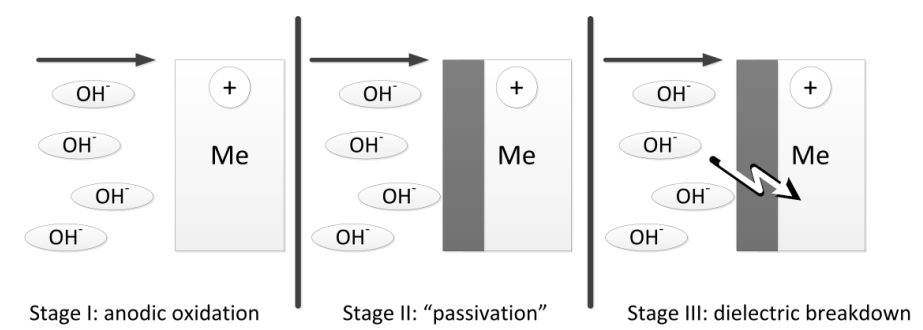

Figure 1. Main stages of an oxide layer formation in the processes of anodizing (stages I - II) and PEO (stages I - III)

Both direct and alternating current can be used for PEO. However, AC regime is preferable, because pores formed during a cathodic breakdown "heal" by molten oxides during the next anodic pulse [3], the electrolyte in the metal vicinity is refreshed and the produced oxide layers are more uniform. Industrial $50-60 \mathrm{~Hz}$ sine-wave AC voltages of $100-600 \mathrm{~V}$ are most frequently used for the PEO processing. Due to the partial rectifying effect of the valve metal oxide, complex sew-like waves are observed in practice (Fig. 2).

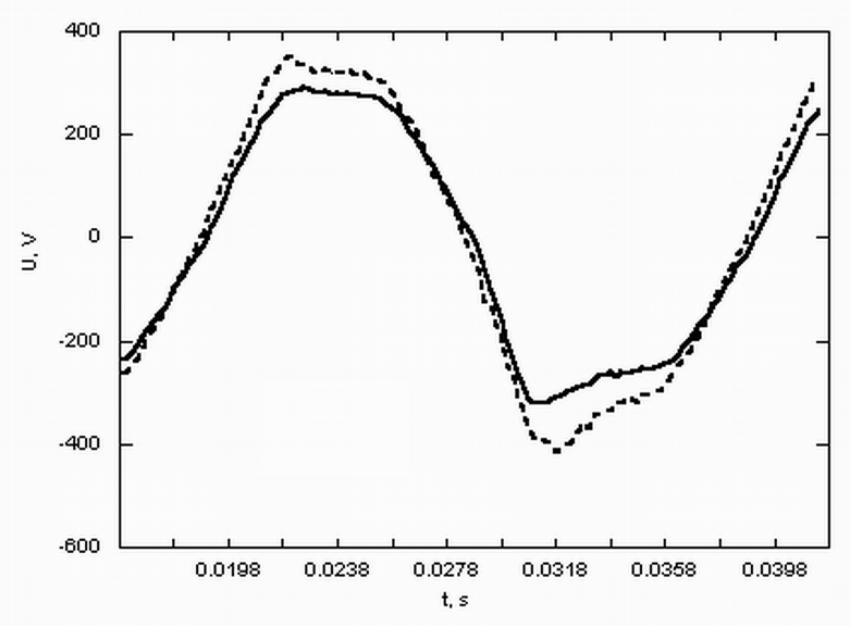

Figure 2. Observed voltage profile of a typical PEO processing of an aluminium alloy in alkaline silicate electrolytes containing $10 \mathrm{~g} / \mathrm{L}$ of $\mathrm{Na}_{2} \mathrm{O} \mathrm{SiO}$ (solid line) or of $\mathrm{Na}_{2} \mathrm{O} 3 \mathrm{SiO}_{2}$ (dotted line). Industrial $50 \mathrm{~Hz}$ sine-wave voltage of $200 \mathrm{~V}$ was supplied for both cases. 
The detailed mechanism of the PEO process has not yet been revealed; however, most investigators (see, for example, $[3,11]$ ) agree that during each AC period several principal steps occur: (1) a barrier oxide layer forms on the boundary between the metal and the electrolyte during the initial anodic semi-period; (2) the potential difference between the two sides of the dielectric oxide layer increases as the anodic semi-period advances until (3) dielectric breakdown takes place. The breakdowns through the oxide layer are accompanied by sparks, so that the process actually occurs in a mode of micro-arc discharges. Fresh portions of the electrolyte are injected into the bare metal surface during the breakdowns, and the process continues as long as the voltage is sufficient for new breakdowns which perforate the growing oxide layer. Relaxation of the metal and oxide and partial reduction of the oxidized species occur during cathodic semi-periods. Gas micro-phase formation (nucleation) and annihilation (cavitation) processes apparently contribute to formation of the oxide layer, but these processes have been scarcely studied because of obvious experimental difficulties.

The production of oxide layers by PEO was most often studied for aluminum and its alloys (for example, in [5-8], [12-17]), magnesium and its alloys ([9, 10] and others), titanium and its alloys (for example, in [18-19]). Studies of PEO on other metals (zirconium [20], zirconium alloys [21] and steel [22]) are scarce.

The various versions of PEO differ from each other with respect to the profile of the applied voltage and the composition of electrolyte. The oxide layer produced always consists of two sub-layers: an outer brittle sub-layer, which typically has a hardness of 500-1000 HV and a porosity of more than $15 \%$, and an inner functional sub-layer, whose typical hardness is 900 $2000 \mathrm{HV}$ and whose typical porosity is $2-10 \%$. The outer brittle sub-layer can be easily removed by polishing, and the inner harder sub-layer can be finished to a smooth marble surface.

Oxide layers can be produced in several types of electrolytes, whose action can differ (see the survey in [11]). Acidic and alkaline electrolytes dissolve moderately the base metal, phosphate and polymer electrolytes passivate it, and fluoride electrolytes interact with it in more complex and less understood ways.

The most frequently used electrolytes for the PEO processing of aluminum and aluminum alloys are aluminate [23, 24], phosphate [24, 25] and, most often, alkaline silicate solutions (for example, $[7,11])$. Magnesium and its alloys are normally PEO processed in alkaline phosphate [26-28] or alkaline silicate electrolytes [10, 29, 30] often containing fluorides [27-30]. Aluminate, phosphate and silicate electrolytes are used for titanium and its alloys (cf. a comparative study in [31]).

Since silicate electrolytes are frequently used for the PEO processing of the valve metals, many aspects of their influence on the properties of produced oxide layers have been intensively studied. For example, it was established that the addition of silicates to the electrolytes stabilizes the oxide layer toward alkaline attacks [12], causes some increase in the thickness of the oxide layers, but reduces their hardness and wear resistance as compared to alkaline electrolytes without silicates [13].

Less information is available about the effect of various forms of "water glasses," i.e., polymer silicates of various composition, on the structure and properties of PEO layers. Little or nothing 
is known about the difference between oxide layers obtained in silicate electrolytes having identical or close element composition, but containing silicates of different $\mathrm{SiO}_{2}$-to- $\mathrm{Na}_{2} \mathrm{O}$ ratios (silicate indexes).

Another point of interest is the influence of the fluoride additives on the structure and properties of the PEO oxide layers produced not on aluminum alloys only, but also on other base metals.

Here we try to summarize these two effects (the role of the silicate index and the influence of fluorides) in a comparative study of the PEO processing of a magnesium alloy and of an aluminum alloy.

\section{Experimental}

Rectangular flat $(3 \times 15 \times 30 \mathrm{~mm})$ specimens of aluminum A5052 alloy (Al as the base and approximately 2.5\% of $\mathrm{Mg}$ ) and magnesium AZ9110D alloy ( $\mathrm{Mg}$ as the base and $8.3-9.7 \% \mathrm{Al}$, 0.15\% Mn min., 0.35-1.0\% Zn, 0.10\% Si max., 0.005\% Fe max., 0.030\% Cu max., 0.002\% Ni max., $0.02 \%$ max. others) were cut, polished with \#1200 grit SiC abrasive paper and rinsed in tap water prior to be PEO processed. The oxidation was performed in AC mode by the industrial $50 \mathrm{~Hz}$ sine voltage at the end current density $6.6 \pm 0.2 \mathrm{~A} / \mathrm{dm}^{2}$ for 30-60 minutes on a homemade $40 \mathrm{kVA}$ PEO station with a water-cooled bath made of stainless steel, which served as the counter electrode. Potassium hydroxide $\mathrm{KOH}$ (Finkelman Chemicals, technical grade), KF (Merck, 99\%), sodium silicate $\mathrm{Na}_{2} \mathrm{O} \mathrm{SiO}_{2} 5 \mathrm{H}_{2} \mathrm{O}$ (pentahydrate, Spectrum, practical grade), and water glass $\mathrm{Na}_{2} \mathrm{O}_{3} \mathrm{SiO}_{2}$ (Spectrum, practical grade) having the silicate indexes $\mathrm{n}=1$ and $\mathrm{n}=3$, respectively were used for the preparation of the electrolytes.

Conductivities and $\mathrm{pH}$ of the electrolytes were measured by a YK-2005WA pH/CD meter, the thickness of oxide layers was first roughly measured by a coating thickness gauge CM- 8825 and then more exactly by SEM. The surface morphology, structure and composition were inspected on SEM JEOL JSM6510LV equipped with an NSS7 EDS analyzer (Correction Method Proza - Phi-Pho-Z was used for the quantitative analysis). Cross-section samples prepared according to standard metallographic protocols [32] were used for SEM, EDS, XRD and microhardness measurements. Microhardness was measured on Buehler Micromet 2100, $\mathrm{HV}_{25}$. X-ray Diffractometer (XRD) Panalytical X'Pert Pro with $\mathrm{Cu} \mathrm{K} \alpha$ radiation $(\lambda=0.154 \mathrm{~nm})$ was used with the full pattern identification made by X'Pert HighScore Plus software package, version 2.2e (2.2.5) by PANalytical B.V. Materials identification and analysis made by the PDF-2 Release 2009 (Powder Diffraction File). Phase analysis identification made by XRD, $40 \mathrm{kV}, 40 \mathrm{~mA}$. The XRD patterns were recorded in the GIXD geometry at $\mathrm{a}=1^{\circ}$ and $5^{\circ}$ in the range of $20-80^{\circ}$ (step size $0.05^{\circ}$ and time per step $2 \mathrm{~s}$ ).

Autolab12 Potentiostat with a standard corrosion cell was used for corrosion tests. Potentials were measured against $\mathrm{Ag} \mid \mathrm{AgCl}$ reference electrode and then related to SHE. 


\section{Results and discussion}

\subsection{PEO of aluminum A5052 alloy in different alkaline silicate electrolytes}

Two sodium silicates were taken for the comparison. The first, $\mathrm{Na}_{2} \mathrm{O} \mathrm{SiO}$, will be hereafter referred to as the " $\mathrm{n}=1$ silicate" and the second, $\mathrm{Na}_{2} \mathrm{O} 3 \mathrm{SiO}_{2}$ will be referred to as the " $\mathrm{n}=3$ silicate," in accordance to their silicate index, that their $\mathrm{SiO}_{2}$-to- $\mathrm{Na}_{2} \mathrm{O}$ ratios. PEO processing was performed in the electrolytes containing $1 \mathrm{gr} / \mathrm{L}(17.9 \mathrm{mmol} / \mathrm{L}) \mathrm{KOH}$ and various amounts of the silicates as specified in Table 1 . Conductivities of the electrolytes were at least 4-5 $\mathrm{mS} / \mathrm{m}$ and all the electrolytes had $\mathrm{pH}=11-13$ (see Table 1).

\begin{tabular}{|c|c|c|c|}
\hline $\mathrm{Na}_{2} \mathrm{O} \cdot \mathrm{nSiO}_{2}$ & $5 \mathrm{~g} / \mathrm{L}$ & $10 \mathrm{~g} / \mathrm{L}$ & $15 \mathrm{~g} / \mathrm{L}$ \\
\hline $\mathrm{Na}_{2} \mathrm{O} \cdot \mathrm{SiO}_{2}(\mathrm{n}=1)$ & $12.68 / 10.27$ & $12.74 / 15.5$ & $12.80 / 22.7$ \\
\hline molarity & 0.021 & 0.041 & 0.062 \\
\hline $\mathrm{Na}_{2} \mathrm{O} \cdot 3 \mathrm{SiO}_{2}(\mathrm{n}=3)$ & $11.08 / 4.53$ & $11.18 / 5.47$ & 11.24 / 6.52 \\
\hline molarity & 0.024 & 0.047 & 0.071 \\
\hline
\end{tabular}

Table 1. Typical electrolyte parameters ( $\mathrm{pH} /$ Conductivity, $\mathrm{mS} / \mathrm{m}$ )

As seen from Table 1, both the basicity and the conductivity are strongly affected by the silicate index, which is not surprising because the molar fraction of sodium oxide is 0.5 for $\mathrm{Na}_{2} \mathrm{O}$ $\mathrm{SiO}_{2}$ and only 0.25 for $\mathrm{Na}_{2} \mathrm{O} 3 \mathrm{SiO}_{2}$. The values of $\mathrm{pH}$ of the electrolytes only weakly depend on the concentration of a given silicate, while their conductivities are roughly proportional to the concentration of $\mathrm{Na}_{2} \mathrm{O} \mathrm{SiO}{ }_{2}$ or $\mathrm{Na}_{2} \mathrm{O} 3 \mathrm{SiO}_{2}$. As one could expect, better conductivities of the " $\mathrm{n}=1$ electrolytes" must facilitate the PEO process.

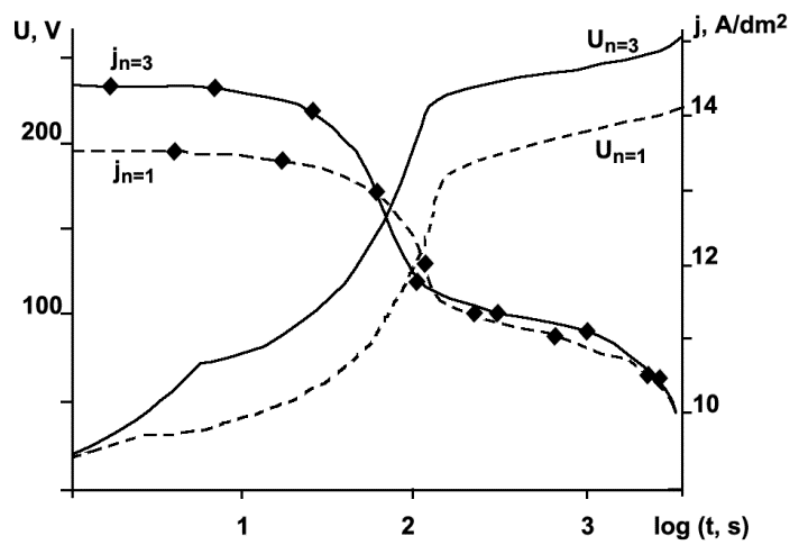

Figure 3. Typical voltage $(U)$ and current density ( $\mathrm{j}$ ) amplitudes in the PEO process of an aluminium alloy in $\mathrm{n}=1$ and $n=3$ electrolytes. 
Indeed, lower current densities are needed for the plasma process initiation when $n=1$ (Fig. 3). As seen from Fig. 3, not only the initial current densities, but also the process voltages are higher for " $\mathrm{n}=3$ electrolytes". Visual changes both in voltage and in current density are observed after 100 - 200 seconds. These changes can indicate that a steady state has been achieved, when only significantly fewer discharges occur and the oxide layer has mainly been formed.

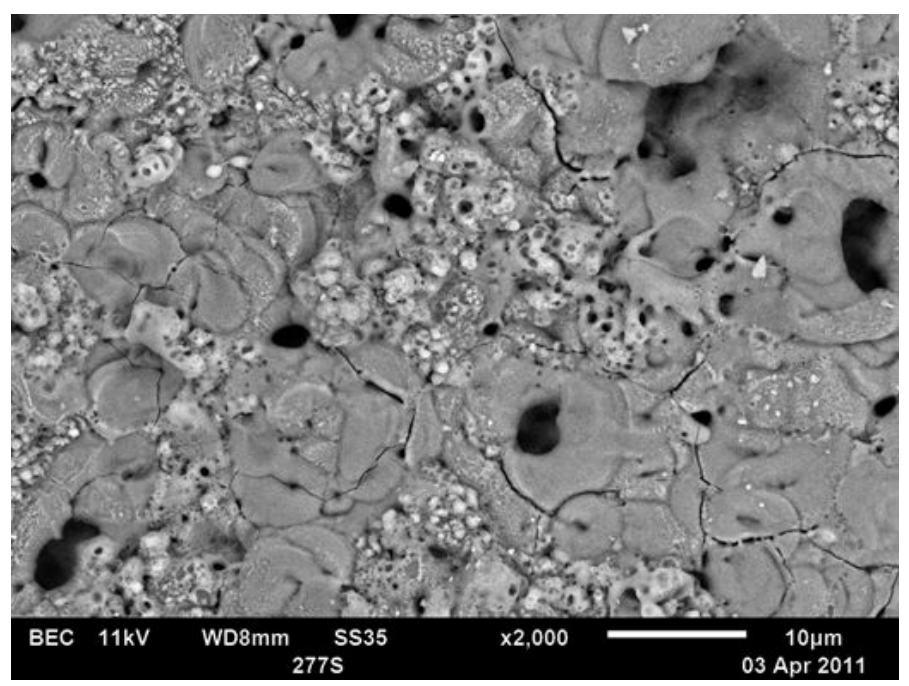

Figure 4. A SEM image (Secondary electron detector) of the morphology of an oxide layer produced by PEO of an aluminium alloy in an alkaline silicate electrolyte.

Oxide layers produced after 30-60 min of PEO have porous morphology with blind "craterlike" pores, which are the results of plasma discharges through the oxide (Fig. 4). No difference in morphology was observed for the two types of electrolytes.

The morphology and elemental composition of a pore obtained by the EDS are presented in Fig. 5 and Table 2. As follows from the data of the elemental analysis, the interior of a pore contains much less silicon and much more aluminum than the exterior close to the surface. This is not surprising, because aluminum comes from inside (from the metal substrate), while silicon is provided by the electrolyte and only with difficulties can penetrate to the depths of the oxide layer. 


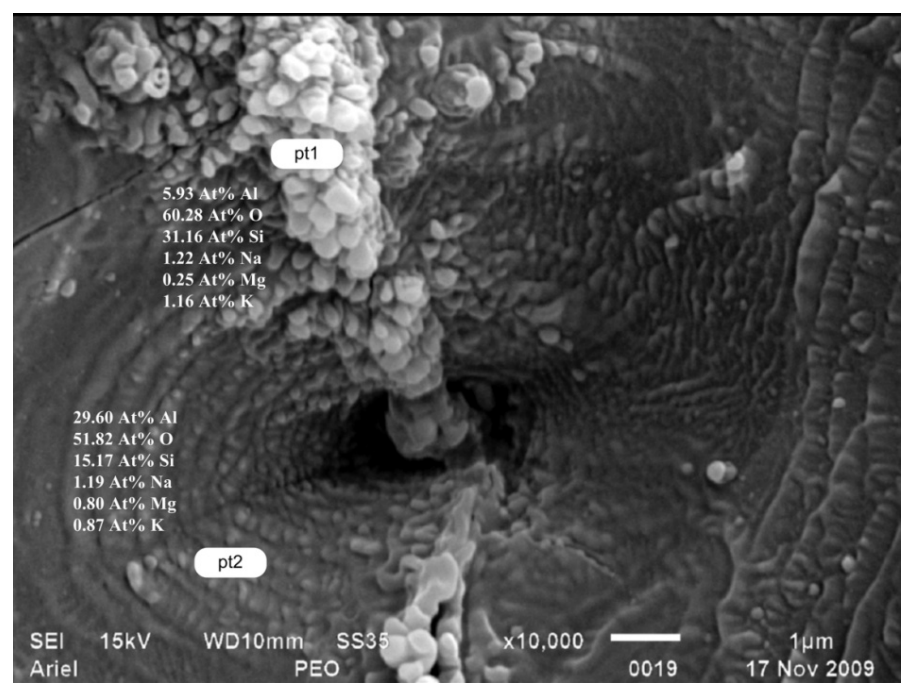

Figure 5. Morphology and elemental composition of a pore at two characteristic points: point 1 (pt1) on the surface of the specimen; point 2 (pt2) inside the pore.

\begin{tabular}{ccccccc}
\hline At.\% & Al & Si & $\mathbf{O}$ & $\mathbf{N a}$ & $\mathbf{M g}$ & $\mathbf{K}$ \\
\hline Point 1 & 5.9 & 31.2 & 60.3 & 1.2 & 0.3 & 1.2 \\
Point 2 & 29.6 & 15.2 & 51.8 & 1.2 & 0.8 & 0.9 \\
\hline
\end{tabular}

Table 2. Element composition of the oxide coating on the surface (point 1) and inside a pore (point 2)

The oxide layers, formed after 30 minutes of PEO, are 20-60 $\mu \mathrm{m}$ thick and consist of two clearly pronounced sublayers: a denser inner sublayer and a loose porous outer sublayer (Fig. 6).
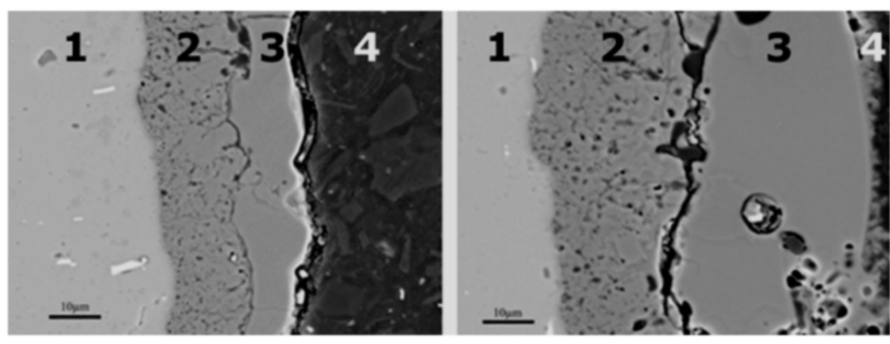

Figure 6. The structure of oxide layers on cross-sections of specimens obtained by PEO in (left image) $0.05 \mathrm{~mol} / \mathrm{L} \mathrm{n=1}$ and (right image) $n=3$ electrolytes: (1) non-oxidized base alloy, (2) inner denser oxidized sublayer, (3) outer loose sublayer, (4) resin wrapping. Back-Scattered Electron SEM image, x1,000. 


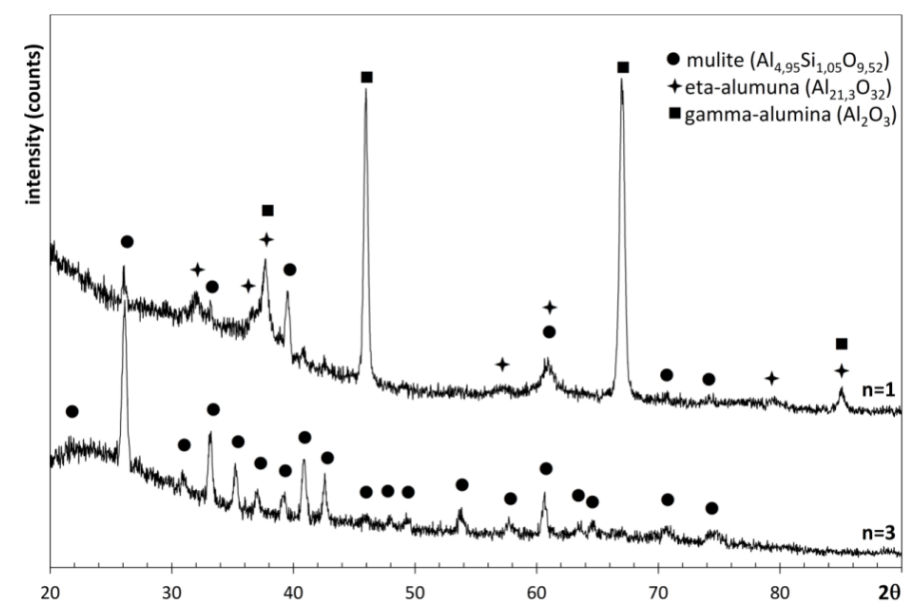

Figure 7. XRD patterns for oxide layers on specimens obtained by PEO in $0.05 \mathrm{~mol} / \mathrm{L} n=1$ and $n=3$ electrolytes. Minor phases are not shown.

While the outer sublayer contains fewer pores, the pores in it are much larger than in the inner sublayer. The mean density of the outer sublayer is lower than of the inner sublayer. Both sublayers are considerably thicker for the " $n=3$ electrolytes", but they contain 2-5 times as much silicon as for the " $\mathrm{n}=1$ electrolytes". XRD phase analysis (Fig. 7) shows that the oxide layer contains $60-70 \%$ of $\gamma$-alumina, $20-30 \%$ of $\eta$-alumina and about $1 \%$ of quartz for the " $n=1$ electrolytes." For "n=3 electrolytes" the oxide layer consists mainly of mullite $3 \mathrm{Al}_{2} \mathrm{O}_{3} 2 \mathrm{SiO}_{2}$ and varied (for different concentrations of the $\mathrm{n}=3$ silicate in the electrolyte) amounts of amorphous silica, quartz and various types of alumina.

\begin{tabular}{|c|c|c|c|c|}
\hline \multirow{2}{*}{$\begin{array}{l}\text { Silicate concentration in } \\
\text { electrolyte, } \mathrm{mol} \cdot \mathrm{L}^{-1}\end{array}$} & \multicolumn{4}{|c|}{ Microhardness, Vickers (HV) } \\
\hline & $\begin{array}{l}\mathrm{n}=1 \text { electrolyte, } \\
\text { outer sublayer }\end{array}$ & $\begin{array}{l}\mathrm{n}=1 \text { electrolyte, } \\
\text { inner sublayer }\end{array}$ & $\begin{array}{l}\mathrm{n}=3 \text { electrolyte, } \\
\text { outer sublayer }\end{array}$ & $\begin{array}{l}\mathrm{n}=3 \text { electrolyte, } \\
\text { inner sublayer }\end{array}$ \\
\hline 0.019 & 840 & 1100 & 770 & 1060 \\
\hline 0.025 & 1130 & 1380 & 1280 & 1570 \\
\hline 0.050 & 890 & 1050 & 710 & 980 \\
\hline 0.075 & 920 & 1630 & 700 & 910 \\
\hline Mean hardness & 945 & 1290 & 865 & 1130 \\
\hline
\end{tabular}

Table 3. Microhardness of oxidized sublayers produced by PEO in electrolytes containing different concentrations of " $n=1$ " and " $n=3$ " silicates measured on cross-sectioned specimens perpendicularly to the section planes.) 
Results of hardness measurements of oxide layers are presented in Table 3. Obviously, alumina-quartz layer formed in the " $n=1$ electrolytes" is harder than mullite layer formed in the " $n=3$ electrolytes."

Corrosion tests were made after a specimen was masked by resin except for a square window having the area of $1 \mathrm{~cm}^{2}$ on the oxidized surface. Thus prepared specimen was held for 1 hour in $1 \% \mathrm{NaCl}$ for the achievement of steady-state corrosion and then its voltammetric curve was measured using Linear Sweep Voltammetry $(25 \mathrm{mV} / \mathrm{sec})$. Broader potential range (normally, $\mathrm{OCP} \pm 500 \mathrm{mV}$ ) was first studied for the determination of the corrosion potential. Narrower potential range of $\pm 50-70 \mathrm{mV}$ relatively to the previously roughly determined corrosion potential was then measured and used for Tafel slope analysis. All potentials were measured against the $\mathrm{Ag} \mid \mathrm{AgCl}$ reference electrode and then recalculated to the standard hydrogen electrode potentials.

The results of thus measured corrosion characteristics of "bare" A15052 alloy and different PEO oxidized specimens are given in Table 4 . As follows from Table 4, corrosion current densities measured on oxidized samples are at least 3-4 times lower than for the untreated alloy. Corrosion potentials for all the oxidized samples are considerably more positive than for the untreated alloy, which evidences the increase of anodic stability in the test solution. The most noble corrosion potentials are observed for lower concentrations of both $n=1$ and $n=3$ silicates and correlate with higher microhardness of oxide layers (Table 3) observed for these concentrations. We could carefully assume that the content of $\gamma$-alumina in an oxide layer plays the key role in the shift of corrosion potentials to the positive direction.

\begin{tabular}{lllll}
\hline $\begin{array}{l}\text { Silicate concentration } \mathrm{n}=1 \text { electrolyte, } \\
\text { in electrolyte, mol.L-1 }\end{array}$ & $\begin{array}{l}\mathrm{n}=1 \text { electrolyte, } \\
\mathrm{E}_{\text {corr }} \mathrm{V} \text { vs. SHE }\end{array}$ & $\begin{array}{l}\mathrm{n}=3 \text { electrolyte, } \\
\mathrm{i}_{\text {corr }} \mathrm{A} / \mathrm{cm}^{2} \times 10^{6}\end{array}$ & $\begin{array}{l}\mathrm{n}=3 \text { electrolyte, } \\
\mathrm{i}_{\text {corr }} \mathrm{A} / \mathrm{cm}^{2} \times 10^{6}\end{array}$ \\
\hline "bare" Al5052 SHE & -1.126 & 15.99 & -0.525 & 0.08 \\
0.013 & & & -0.815 & 2.66 \\
0.025 & -0.497 & 3.60 & -0.998 & 0.98 \\
0.050 & -0.796 & 4.30 & -0.972 & 1.68 \\
0.075 & & & & \\
0.100 & -0.942 & 1.93 & & \\
0.150 & -0.995 & 3.77 & & \\
\hline
\end{tabular}

Table 4. Corrosion current densities and potentials of Al5052 alloy oxidized in different electrolytes.

The results summarized in Table 4 are better than those obtained for anodizing [14], similar to those obtained for much more expensive protection methods and similar or batter than those obtained by PEO in other silicate electrolytes [6, 15-17]. All the measurements evidence that specimens treated in " $n=3$ electrolytes" have better corrosion protection than those treated in "n=1 electrolytes." The microscopic inspection of cross-sections evidences (Fig. 4) that even though the outer sublayer produced in " $n=3$ electrolytes" contains large caverns and the inner 
sublayer looks more porosive than for the " $\mathrm{n}=1$ electrolytes", the larger thickness of the layer produced in the " $\mathrm{n}=3$ electrolytes" presents a more difficult barrier for the diffusion of corrosive media and therefore forms better protection of the metal substrate. It deserves to be reminded that the oxide layers produced in the " $n=1$ electrolytes" only contain oxide phases (alumina and quartz), in contrast to the mullite layer produced in the " $n=3$ electrolytes." Obviously, the milder mullite better fills pores in the oxide layer than harder oxides do. Somewhat similar results were obtained by another research group [7] for another Al alloy (2219) and also demonstrated that higher silicate contents in silicate-alkaline electrolytes increase the corrosion resistance of PEO coatings.

\subsection{Fluoride influence on the properties of oxide layer produced by PEO}

The surface of PEO layers produced on both the magnesium and the aluminum alloys is normal for PEO coatings and consists of "volcanic" pores chaotically distributed on a fused surface (Fig. 4).

Long PEO processing times (30-90 min) result in thick coatings for both alloys, but the initial stages demonstrate a clear difference between the two metal alloys. For the PEO treatment in the alkaline silicate electrolyte $\left(0.08 \mathrm{~mol} / \mathrm{L} \mathrm{KOH}+0.08 \mathrm{~mol} / \mathrm{L} \mathrm{Na}_{2} \mathrm{SiO}_{3}\right)$ without the fluoride addition, the 15 minute process produces approximately $20 \mu \mathrm{m}$ thick non-continuous oxide layer on the magnesium alloy and only about $5 \mu \mathrm{m}$ thick non-continuous layer on the aluminum alloy (Fig. 8).
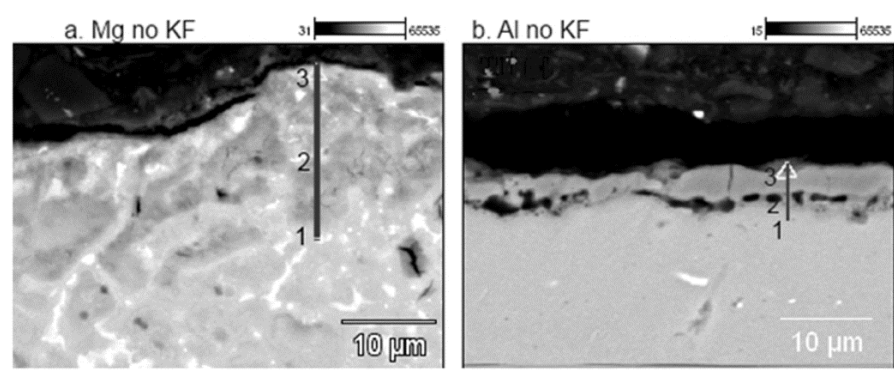

Figure 8. SEM images (x3000) with EDS linear scans of cross-sectioned PEO layers on (a) the magnesium and (b) aluminum alloys obtained after 15 minute oxidation. The black zone in the topmost parts is polymer tar fixing the specimen. The base metals are in the bottom part of each image. The element composition at points 1, 2, 3 of each image is specified in Table 5.

Both on the magnesium and on the aluminum alloys the coating is porous, but the porous are blind. Element compositions at points 1, 2 and 3 along lines drawn from the pure base metal to the outer border of the coatings (Fig. 8) are given in Table 5. 


\begin{tabular}{llll}
\hline \multicolumn{2}{c}{ Mg alloy } & \multicolumn{1}{c}{ Al alloy } \\
\hline Point 1 & Mg 82 at\%, Al 8 at\%, O 9 at\%, Si 1 at\% & Point 1 & Al 94 at\%, Mg 2 at\%, O 4 at\% \\
\hline Point 2 & Mg 67 at\%, Al 13 at\%, O 17 at\%, Si 3 at\% & Point 2 & Al 61 at\%, Mg 3.5 at\%, O 34 at\%, Si 1.5 at\% \\
\hline Point 3 & Mg 60 at\%, Al 9 at\%, O 27 at\%, Si 4 at\% & Point 3 & Al 70 at\%, Mg 2.5 at\%, O 15 at\%, Si 9.5 at\%, K 3 \\
& & & at\% \\
\hline
\end{tabular}

Table 5. Element compositions at representative points 1, 2 and 3 as shown in Fig. 8.

As follows from Fig. 8 and Table 5, the oxidized layer on the magnesium alloy is not only thicker, but also more uniform than that on the aluminum alloy, for which large voids containing relatively high amounts of oxygen are formed between the base metal and the oxide layer. It deserves to be noted that the percentage of oxygen is lower than what should be expected according to the stoichiometry of magnesium and aluminum oxides $(\mathrm{Mg}: \mathrm{O}=1: 1$ and $\mathrm{Al}: \mathrm{O}=2: 3$ ). Therefore, the oxide layer never consists of the oxides only, but contains some excess metal atoms.

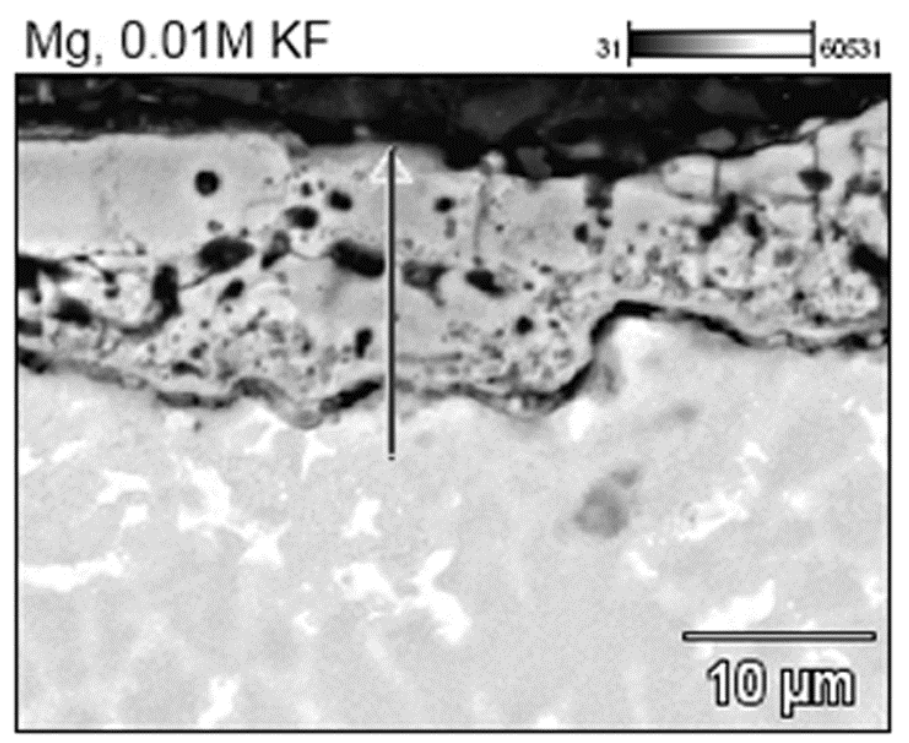

Figure 9. BSE SEM images (x3000) with EDS linear scans of cross-sectioned PEO coating on the magnesium alloy obtained after 15 minute oxidation in the electrolyte containing $0.01 \mathrm{~mol} / \mathrm{L} \mathrm{KF}$.

As KF has been added to the electrolytes, the situation with the oxidation of magnesium alloy becomes different. While the total thickness of the coating remains relatively the same $(\sim 20$ $\mu \mathrm{m}$ after 15 minutes), its structure and composition are clearly distinguished from what was observed without the fluoride. Already for the lowest studied KF concentration $(0.01 \mathrm{~mol} / \mathrm{L})$ the coating is continuous and consists of two very different sublayers (Fig. 9). The inner 
sublayer is only 2-3 $\mu$ m thick and contains about 70 at $\%$ of $\mathrm{Mg}, 25$ at $\%$ of $\mathrm{O}$ and 5 at $\%$ of $\mathrm{Al}$. The outer sublayer is 15-18 $\mu \mathrm{m}$ thick, porous and contains large voids filled by light elements (darker sites in Fig. 9). The typical composition of the outer layer is $50-60$ at $\%$ O, 35-40 at $\% \mathrm{Mg}$, 10 at $\% \mathrm{Si}$ and 2-4 at\% Al. As the content of KF in the electrolyte increases, the structure of the layers does not change, but significant amounts of fluorine are detected in the coating.

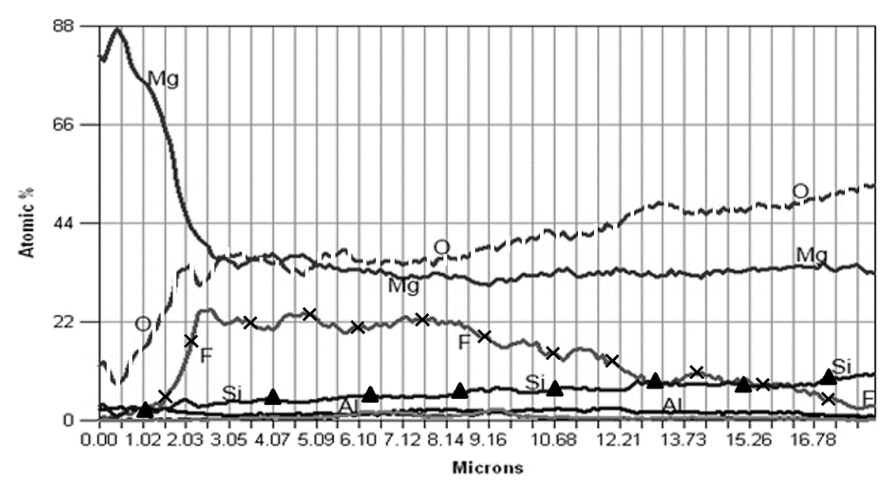

Figure 10. Element composition profiles (EDS linear scan) across the PEO coating on the magnesium alloy obtained after 15 minute oxidation in the electrolyte containing $0.2 \mathrm{~mol} / \mathrm{L} \mathrm{KF}$.

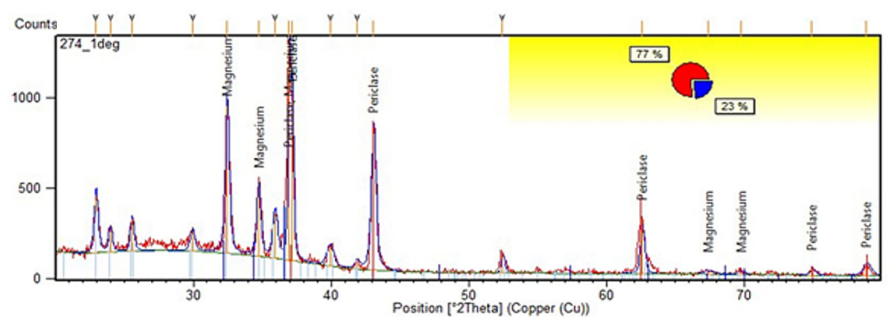

Figure 11. Small angle $\left(1^{\circ}\right)$ XRD pattern for the surface of the PEO coating on the magnesium alloy obtained after 15 minute oxidation in the electrolyte containing $0.02 \mathrm{~mol} / \mathrm{L} \mathrm{KF}$.

Interestingly, the maximal amount of fluoride was detected in the most inward part of the outer sub-layer (Fig. 10). According to small angles (10-5 $\left.5^{\circ}\right)$ XRD measurements, the surface consists of Periclase $\mathrm{MgO}$ (77\%) and metal Mg (23\%). Deeper layers of the coating demonstrate the increase of $\mathrm{Mg}$ at the expense of $\mathrm{MgO}$. No fluorine-containing phases could be identified with confidence (Fig. 11). 


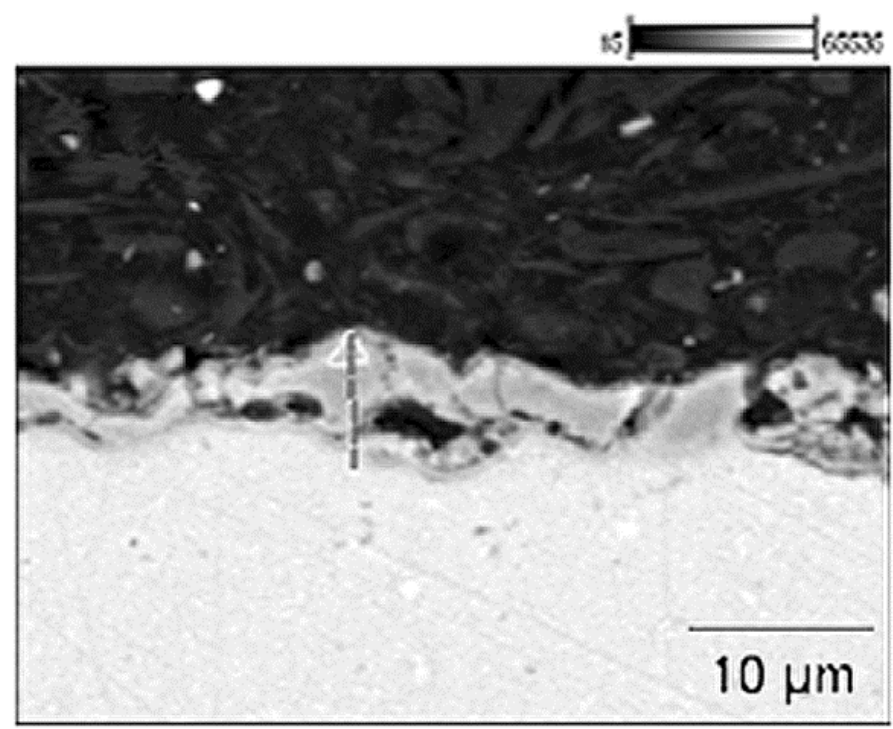

Figure 12. BSE SEM images ( $\times 3000$ ) with EDS linear scans of cross-sectioned PEO coating on the aluminum alloy obtained after 15 minute oxidation in the electrolyte containing $0.2 \mathrm{~mol} / \mathrm{L} \mathrm{KF}$.

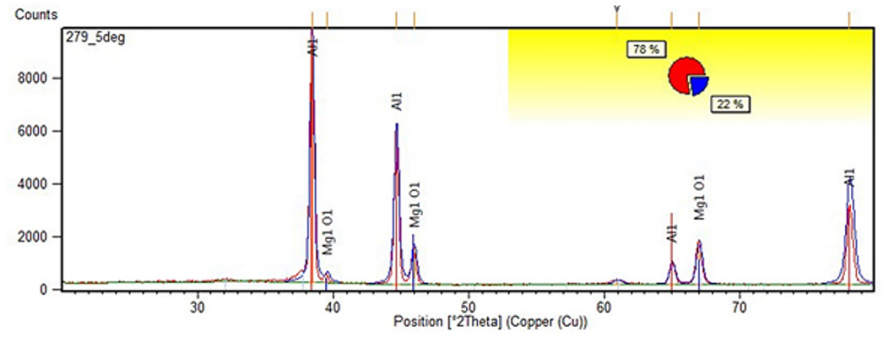

Figure 13. Small angle $\left(5^{\circ}\right)$ XRD pattern for the surface of the PEO coating on the aluminum alloy obtained after 15 minute oxidation in the electrolyte containing $0.05 \mathrm{~mol} / \mathrm{L} \mathrm{KF}$.

The addition of KF to the electrolytes for the PEO processing of the aluminum alloy has another effect. While for lower concentrations of KF $(<0.05 \mathrm{~mol} / \mathrm{L})$ only a very thin porous coating layer is formed, higher KF contents result in the formation of 5-10 $\mu \mathrm{m}$ oxide layer. As the thickness of the coating increases, two sublayers are revealed. As for the magnesium alloy, the thin inner sublayer is denser and the thicker outer one is more porous (Fig. 12). As evidenced by EDS, the outer sublayer contains 60 at $\%$ of $\mathrm{O}$ and 40 at $\%$ of $\mathrm{Al}$. As much as $9 \%$ fluorine is found in the inward part of the outer sublayer. XRD measurements show that the surface ( $1^{\mathrm{o}}$ incident beam) consists of two crystal phases, whose composition is $\mathrm{Al}_{2} \mathrm{MgO}_{4}(56 \%)$ and $\mathrm{MgO}$ 
(44\%). Deeper layers (5\% incident beam) are formed by metal $\mathrm{Al}(78 \%)$ and $\mathrm{MgO}(22 \%)$. A sample of an XRD pattern is given in Fig. 13.

The most obvious observation, which can be made from the comparison of the PEO of the magnesium and of the aluminum alloys, is that magnesium is oxidized much more easily than aluminum. While for all the studied magnesium systems $20 \mu \mathrm{m}$ coating was produced after 15 minutes of the PEO, only 5-10 $\mu$ m coating on the aluminum alloy could be obtained for the same process time. An interesting issue is the ratio "Mg:Al" at different depth of the coatings (Table 6).

\begin{tabular}{lllll}
\hline & $\mathbf{C}_{\mathrm{KF}}, \mathbf{m o l} / \mathbf{L}$ & Base metal & Inner sublayer & Outer sublayer \\
\hline \multirow{3}{*}{ Mg alloy } & 0 & 10.3 & $6.7^{*}$ & \\
& 0.01 & 10.3 & 14 & 8.2 \\
& 0.1 & 10.3 & 15 & 6.4 \\
\hline \multirow{3}{*}{ Al alloy } & 0 & 0.02 & 0.06 & 0.04 \\
& 0.01 & 0.02 & 0.04 & 0.06 \\
& 0.1 & 0.02 & 0.04 & 0.05 \\
\hline
\end{tabular}

*No sublayers were observed for this PEO layer.

Table 6. "at\% $\mathrm{Mg}$ : at\% $\mathrm{Al}$ " ratio at different depths.

As follows from Table 6, magnesium content at the inner sublayer is always higher than in the base metal, except for the oxidation of the magnesium alloy in the electrolyte containing no fluoride, when no sublayers can be seen. The trend is less straightforward for the outer sublayer, which can be explained by the fact that the latter is thicker, more porous and much less uniform. XRD phase analysis confirms than the key role at the initial stage of the oxidation is played by magnesium oxide and only on the surface aluminum starts to be oxidized to form $\mathrm{Al}_{2} \mathrm{MgO}_{4}$. These can be explained by two facts: (1) that the amphoteric aluminum is readily dissolved by the alkaline electrolyte while magnesium is not; (2) that according to Ellingham diagrams [33] the oxidation of magnesium is thermodynamically more favorable than that for aluminum in the entire range of temperatures below $1500 \mathrm{~K}$.

Many authors report that they could not identify a fluoride containing phase in PEO coatings on aluminum or magnesium alloys obtained in alkaline fluoride-containing electrolytes (see, for instance [34-37]). This is consistent with our XRD observation; however we could clearly see the presence of fluoride on EDS cross-sectional profiles of the coatings (Fig. 4). This means that considerable amounts of amorphous fluorides are found in the coatings very close to the base metal. Summarizing, the action of fluoride additives can be assumed as follows: (1) fluoride anions are first chemisorbed to the metal surface and create on it barrier layer; (2) as the dielectric breakdown occurs, oxide layer is formed due to the exchange of fluorine by oxygen atoms from the electrolyte; (3) fluoride remains in the vicinity of the metal and takes part in the formation of an amorphous phase. This process is much more favorable for the 
magnesium alloy due to the easier breakdown of magnesium fluoride as compared to aluminum fluoride.

\section{Conclusions}

Plasma Electrolytic Oxidation in alkaline silicate electrolytes containing 0.013-0.150 mol/L of sodium silicates having silicate index $n=1$ or $n=3$, was performed on Al5052 aluminum alloy. For all the electrolytes studied, 20-90 $\mu \mathrm{m}$ thick oxide layer was obtained and its composition, structure and properties were studied. For each sample, the oxidized layer consists of a denser inner and looser outer sublayer. While for " $n=1$ electrolytes" the oxidized layer is mainly formed by several kinds of alumina, the principal constituent of the oxidized layer for " $n=3$ electrolytes" is mullite.

Measurements of microhardness evidenced that it is apparently not influenced by the kind of silicate $(n=1$ or $n=3)$ and by its concentration in the electrolyte.

Electrolytes with silicate index $n=3$ ensure better corrosion protection than those with $n=1$. This might be caused by the milder and more plastic nature of the oxide layer produced in the " $n=3$ electrolutes" as compared to those produced in the " $n=1$ electrolytes."

Corrosion protection parameters are significantly better for all PEO oxidized samples than for the untreated Al5052 alloy.

The formation of PEO coating on magnesium and aluminum alloys in the presence of fluoride starts with the fluorination of the metal surface and formation of a dielectric metal fluoride layer. Electric breakdowns destruct this layer and form oxide layers containing also amorphous fluorides.

The fluoride-supported PEO process proceeds more easily for the magnesium than for the aluminum alloys. This difference might be caused by the easier breakdown of the dielectric layer containing magnesium fluoride as compared to that containing aluminum fluoride. This is consistent with the values of dielectric permeability of magnesium fluoride (4.87) [38] and of aluminum fluoride (2.2) [39].

The external surface of the coating is enriched by magnesium as compared to the base metal.

\section{Author details}

Alex Lugovskoy* and Michael Zinigrad

*Address all correspondence to: lugovsa@ariel.ac.il

Chemical Engineering Department, Ariel University Center of Samaria, Ariel, Israel 


\section{References}

[1] Hussein, R. O, Nie, X, Northwood, D. O, Yerokhin, A, \& Matthews, A. Spectroscopic study of electrolytic plasma and discharging behaviour during the plasma electrolytic oxidation (PEO) process. J. Phys. D: Appl. Phys. (2010).

[2] Curran, J. A, \& Clyne, T. W. Porosity in plasma electrolytic oxide coatings. Acta Materialia (2006). , 54-1985.

[3] Sah, S. P, Tsuji, E, Aoki, Y, \& Habazaki, H. Cathodic pulse breakdown of anodic films on aluminium in alkaline silicate electrolyte- Understanding the role of cathodic halfcycle in AC plasma electrolytic oxidation. Corrosion Science (2012). , 55-90.

[4] Barik, R. C, Wharton, J. A, Wood, R. J. K, Stokes, K. R, \& Jones, R. L. Corrosion, erosion and erosion-corrosion performance of plasma electrolytic oxidation (PEO) deposited $\mathrm{Al}_{2} \mathrm{O}_{3}$ coatings. Surface \& Coatings Technology (2005). , 199-158.

[5] Xue, W, Shi, X, Hua, M, \& Li, Y. Preparation of anti-corrosion films by microarc oxidation on an Al-Si alloy. Applied Surface Science (2007). , 253-6118.

[6] Nie, X, Meletis, E. I, Jiang, J. C, Leyland, A, Yerokhin, A. L, \& Matthews, A. Abrasive weary corrosion properties and TEM analysis of $\mathrm{Al}_{2} \mathrm{O}_{3}$ coatings fabricated using plasma electrolysis. Surface and Coatings Technology (2002). , 149-245.

[7] Alsrayheen, E, Campbell, B, Mcleod, E, Rateick, R, \& Birss, V. Exploring the effect of alkaline silicate solution composition on the ac/dc spark anodization of Al-Cu Alloys. Electrochimica Acta (2012). , 60-102.

[8] Venugopal, A, Panda, R, Manwatkar, S, \& Sreekumar, K. Rama Krishna L., Sundararajan G. Effect of micro arc oxidation treatment on localized corrosion behaviour of AA7075 aluminum alloy in 3.5\% $\mathrm{NaCl}$ solution. Trans. Nonferrous Met. Soc. China (2012).

[9] Guo, H, \& An, M. Xu Sh., Huo H., Microarc oxidation of corrosion resistant ceramic coating on a magnesium alloy. Materials Letters (2006). , 60-1538.

[10] Chen, F, Zhou, H, \& Yao, B. Qin Zh., Zhang Q. Corrosion resistance property of the ceramic coating obtained through microarc oxidation on the AZ31 magnesium alloy surfaces. Surface \& Coatings Technology (2007). , 201-4905.

[11] Yerokhin, A. L, Nie, X, Leyland, A, Matthews, A, \& Dowey, S. J. Plasma electrolysis for surface engineering. Surface and Coatings Technology (1999). , 122-73.

[12] Moon, S, \& Jeong, Y. Generation mechanism of microdischarges during plasma electrolytic oxidation of $\mathrm{Al}$ in aqueous solutions, Corrosion Science (2009). , 51(2009), 1506-1512.

[13] Polat, A, Makaracib, M, \& Ustac, M. Influence of sodium silicate concentration on structural and tribological properties of microarc oxidation coatings on 2017A aluminum alloy substrate. Journal of Alloys and Compounds (2010). , 504-519. 
[14] Zabielski, C. V, \& Levy, M. Study of Type II and Type III Anodized Al in Aqueous DS2 Solutions. U.S. Army Research Laboratory Environmental Effects. In: Proceedings of the TRI-Service conference on corrosion. Plymouth, Massachusetts 12-14 May (1992). Avavilable on http://namis.alionscience.com/conf/tscc/search/pdf/AM026095.pdf., 5052-0.

[15] Tseng ChCh., Lee J.-L., Kuo Tz.-H., Kuo Sh.-N., Tseng K.-H. The influence of sodium tungstate concentration and anodizing conditions on microarc oxidation (MAO) coatings for aluminum alloy. Surface \& Coatings Technology (2012). , 206-3437.

[16] Raj, V. Mubarak Ali M. Formation of ceramic alumina nanocomposite coatings on aluminium for enhanced corrosion resistance. J. Mat. Proc. Technology (2009). , 209-5341.

[17] Wei, C. B, Tian, X. B, Yang, S. Q, Wang, X. B, Fu, R. K. Y, \& Chu, P. K. Anode current effects in plasma electrolytic oxidation. Surface \& Coatings Technology (2007). , 201-5021.

[18] Li, Y, Yao, B, Long, B. Y, Tian, H. W, \& Wang, B. Preparation, characterization and mechanical properties of microarc oxidation coating formed on titanium in $\mathrm{Al}(\mathrm{OH})_{3}$ colloidal solution. Applied Surface Science (2012). , 258-5238.

[19] Wang, Y. M, Jiang, B. L, Lei, T. Q, \& Guo, L. X. Microarc oxidation coatings formed on $\mathrm{Ti}_{6} \mathrm{Al}_{4} \mathrm{~V}$ in $\mathrm{Na}_{2} \mathrm{SiO}_{3}$ system solution: Microstructure, mechanical and tribological properties. Surface \& Coatings Technology (2006). , 201-82.

[20] Pauporté, T, Finne, J, Kahn-harari, A, \& Lincot, D. Growth by plasma electrolysis of zirconium oxide films in the micrometer range. Surface \& Coatings Technology (2005). , 199-213.

[21] Cheng, Y, Matykina, E, Arrabal, R, Skeldon, P, \& Thompson, G. E. Plasma electrolytic oxidation and corrosion protection of Zircaloy-4. Surface \& Coatings Technology (2012). , 206-3230.

[22] Wang, Y. Jiang Zh., Yao Zh. Preparation and properties of ceramic coating on Q235 carbon steel by plasma electrolytic oxidation. Current Applied Physics (2009). , 9-1067.

[23] Xin ShG., Song L.-X., Zhao R.-G., Hu X.-F. Properties of aluminium oxide coating on aluminium alloy produced by micro-arc oxidation. Surface \& Coatings Technology (2005). , 199-184.

[24] Shen, D, \& Wang, J. Y.-L., Nash Ph., Xing G.-Zh. Microstructure, temperature estimation and thermal shock resistance of PEO ceramic coatings on aluminium. J. materials processing technology (2008). , 205-477.

[25] Snizhko, L. O, Yerokhin, A. L, Pilkington, A, Gurevina, N. L, Misnyankin, D. O, Leyland, A, \& Matthews, A. Anodic processes in plasma electrolytic oxidation of aluminium in alkaline solutions. Electrochimica Acta (2004). , 49-2085. 
[26] Timoshenko, A. V. Magurova Yu.V. Investigation of plasma electrolytic oxidation processes of magnesium alloy MAunder pulse polarisation modes. Surface \& Coatings Technology (2005). , 2-1.

[27] Boinet, M, Verdier, S, Maximovitch, S, \& Dalard, F. Plasma electrolytic oxidation of AM60 magnesium alloy: Monitoring by acoustic emission technique. Electrochemical properties of coatings. Surface \& Coatings Technology (2005). , 199-141.

[28] Hsiao, H, Tsung, Y, Ch, H, Tsai, W, Anodization, T, \& Of, A. Z. D magnesium alloy in silicate-containing electrolytes. Surface \& Coatings Technology (2005). , 199-127.

[29] Duan, H. Yan Ch., Wang F. Effect of electrolyte additives on performance of plasma electrolytic oxidation films formed on magnesium alloy AZ91D. Electrochimica Acta (2007). , 52-3785.

[30] Liang, J, Guo, B, Tian, J, Liu, H, Zhou, J, \& Xu, T. Effect of potassium fluoride in electrolytic solution on the structure and properties of microarc oxidation coatings on magnesium alloy. Applied Surface Science (2005). , 252-345.

[31] Yerokhin, A. L, Nie, X, Leyland, A, \& Matthews, A. Characterisation of oxide films produced by plasma electrolytic oxidation of a Ti-6Al-4V alloy. Surface \& Coatings Technology (2000). , 130-195.

[32] Vander Voort GF., editor. ASM Handbook, and Microstructures. (2004). ASM International., 09-Metallography

[33] MIT educational materialshttp://web.mit.edu/2.813/www/readings/Ellingham_diagrams.pdfaccessed on August 31, (2012).

[34] Wang ZhWu L., Cai W., Shan A, Jiang Zh. J. Effects of fluoride on the structure and properties of microarc oxidation coating on aluminium alloy. Alloys and Compounds (2010). , 505-188.

[35] Wang, K, Koo, B, Lee, H, Ch, G, Kim, Y, Lee, J, \& Byon, S. -H. E. Effects of electrolytes variation on formation of oxide layers of $6061 \mathrm{Al}$ alloys by plasma electrolytic oxidation. Trans. Nonferrous Met. Soc. China (2009). , 19-866.

[36] Gnedenkov, S. V, Khrisanfova, O. A, Zavidnaya, A. G, Sinebrukhov, S. L, Gordienko, P. S, Iwatsubo, S, \& Matsui, A. Composition and adhesion of protective coatings on aluminium. Surface and Coatings Technology (2001). , 145-146.

[37] Lin, C. S, \& Fu, Y. C. J. Characterization of anodic films of AZ31 magnesium alloys in alkaline solutions containing fluoride and phosphate anions. J. Electrochem. Soc. (2006). BB424., 417.

[38] Duncanson, A, \& Stevenson, R. W. H. Some Properties of Magnesium Fluoride crystallized from the Melt. Proc.Phys.Soc. (1958). , 72, 1001.

[39] Table of Dielectric ConstantsASI Instruments Web Site. http://wwwasiinstr.com/ technical/Dielectric\%20Constants.htmaccessed on November 3, (2012). 